\title{
Pragmatic Differences between Chinese and English Apologies in Cross-cultural Communication
}

\author{
Chengcui Hu \\ Yunnan College of Business Management, Yunnan, China, Yunnan
}

Keywords: Intercultural communication; apology; difference analysis

\begin{abstract}
Apology is the basic expression of moral accomplishment, an important part of civilized etiquette and an indispensable link in social interaction. Over the years, it has gradually aroused extensive discussion among language researchers. Whether in Chinese or English, apologies are expressed in a variety of ways. The choice of specific terms depends on specific contextual features. Due to the different contextual features, a great disparity of value attitudes has been formed. Anglo-Americans tend to preserve their faces, so they are willing to argue for themselves. And Chinese people often choose to apologize directly because they think about face. Based on the relevant strategies of apology, this paper elaborates on the relevant expressions of apology in English and Chinese, and analyses their specific differences and reasons, so that we can explore the real differences in the cultural core of apology from the language point of view and on the basis of language materials.
\end{abstract}

Due to the differences of value orientation, emotional traits and other elements, there are many differences between English and Chinese, among which apology is the typical one. Apology is an emotional speech act. Over the years, it has gradually aroused extensive discussion among language researchers. Apology is a key link for us to maintain a harmonious interpersonal relationship and establish a perfect personal image. It has become an important research topic in linguistics. Based on the relevant strategies of apology, this paper elaborates on the relevant expressions of apology in English and Chinese, and analyses their specific differences and reasons, so that we can explore the real differences in the cultural core of apology from the language point of view and on the basis of language materials.

\section{Language forms of apologies in English and Chinese}

Whether Chinese language culture or English language culture chooses apology language is directly related to context. Although apologies are expressed in different ways, they tend to adopt more advanced forms of expression with the upgrading of contextual level. For example, when two people with close emotional relationship need one party to make an apology because of some misunderstanding or contradiction, the form of apology is relatively simple in a more private and personal environment. In a relatively formal social environment, more formal expressions of apology are needed. Both Eastern and Western cultures regard apology as a virtue and respect it. As shown in Table 1. 
Table 1. Chinese and Western expressions of apology

\begin{tabular}{|l|l|}
\hline English apologies & Chinese apologies \\
\hline Pardon me & sorry \\
\hline Oh, my fault & impolite \\
\hline $\begin{array}{l}\text { May I offer you my profoundest } \\
\text { apologies? }\end{array}$ & I apologize \\
\hline I apologize for & I apologize to you \\
\hline
\end{tabular}

In Chinese and English cultures, apology is relatively simple when offence is mild. This is the similarity between the two languages and cultures. But it must be based on a relatively simple context, or in some informal social occasions. In the relatively advanced situation, although the relationship between the two communicators is relatively close, they also need to use a higher-level form of apology. This shows that in both Chinese and English cultures, great importance has been attached to the context of apology terms, and that cultural factors in context have an impact on the choice of language strategies.

Therefore, in the use of apology in English and Chinese, the understanding of cross-cultural factors is very important. Compared with the conventional language communication, the content of apology information is more enriched. It includes not only the emotional factors of the speaker, but also the purpose factors of the speaker. Therefore, when using the apology language, whether the apologist or the apologized party, we need to consider the influence of many factors in the context in order to avoid the impact of cross-cultural conflict on the use of foreign languages.

\section{Differences and reasons between English and Chinese apologies}

\section{Differences in Understanding of Apology}

Differences in the Frequency of Apology Use

The influence of social distance on apology in Chinese and English

The: Impact of Relative Power on Apologies in Chinese and English

Figure 1. Differences and Reasons between English and Chinese Apologies

As shown in figure 1, a detailed analysis is presented below.

\subsection{Differences in understanding of apology}

First of all, there are qualitative differences between Chinese and English cultures in the understanding of apology. J. Holmes explains apology: "Assuming A is the apologia and B is the offender, apologizing is to make up for the offence, apologizing to B to save B's face and restore the balance between A and B's speech act."Explanations generally revolve around the motive of "apologizing", that is, to save the face of the object of action, so as to ensure the normal operation of interpersonal relations. Compared with the utilitarian nature of English apology, apology in Chinese culture tends to be more humanistic, focusing on the actor's own feelings and feeling guilty, so apologies must be made.

However, people in English-speaking countries tend to regard etiquette as a means of behavior, 
focusing on external forms rather than conscious feelings. Chinese people's understanding of apology shows the etiquette characteristics of Chinese culture. Specifically speaking, it pays attention to morality and human feelings. Apology originates from the inside and manifests itself from the outside. Although there are differences in the understanding of "apology" between China and Britain, they regard apology as a necessary social behavior, which is a polite expression with compensatory significance and aims at maintaining harmonious communication.

\subsection{Differences in the frequency of apology use}

In the use of apology, British and American people use more frequently than Chinese people. As far as British and Americans are concerned, apologies are a key part of daily necessities. Even if the degree of offence can be ignored, British and American people should use apology, regardless of time, occasion and object. They apologize anywhere and anytime because Anglo-American culture focuses on individuals and highlights their own interests. There are clear boundaries between people.They are afraid to offend others by their words and deeds. They are always on guard against their "boundary" actions. Breathing offends other people's sensory organs, coughing and sneezing can spread germs, so these seemingly small behavior, British and American people have to say "I'm sorry". In the view of Chinese, apologizing is a solemn act, which must be equal to the degree of offence. Therefore, there are differences in the frequency of apology between Chinese and English.

Anglo-American people attach great importance to their differences of opinion. Even if it is an insignificant conflict, they will magnify it as a positive manifestation of democratic spirit. For them, disagreement is not terrible. They will enjoy it, unlike the Chinese people who try to contain it. British and American people actively use apology to ease their differences, so the apology rate is higher than that of Chinese people. In actual communication, Chinese people usually feel trivial, and British and American people will regard it as privacy. Because British and American people regard many things as privacy, including time, space and so on, their privacy is often violated. If privacy is violated, an immediate apology is needed. As a result, the rate of apology in society is much higher than in China.

\subsection{The influence of social distance on apology in Chinese and English}

Social distance refers to the degree of intimacy between the two sides of apology, which includes strangers, acquaintances, familiar people, intimate people and other levels. The influence of social distance on apology is significantly different between Chinese and English. For those who don't know, the Chinese often adopt a single form of apology, usually direct apology, such as saying "sorry". For relatives, they often choose informal expressions, such as "dear, I'm wrong, forgive me". For those who know well, people with general familiarity tend to choose more formal and complex means of apology, such as "XX, I'm sorry". Don't be so impulsive. I'm sorry. I apologize to you."

By contrast, British and American apologies to people they know are less solemn and casual to close relatives. Chinese hardly apologize to their relatives, especially between parents and children. According to the survey, only $10 \%$ of Chinese parents apologize to their children after their parents forgot to fulfill their promises to buy gifts. But in the same situation, most American presidents will say "sorry" directly and choose to make up for their promises.

\subsection{The impact of relative power on apologies in Chinese and English}

Relative power refers to the social relationship between the offender and the offender in terms of seniority, status, etc. Social relations greatly affect the communication between people. In Chinese 
culture, the principles of interpersonal morality are: subordinate to superiors, subordinate to elders, respect for the elderly and leaders, with age and hierarchy as the most important factors. As far as Chinese are concerned, in order to ensure orderly interpersonal relationships, if offenders are of high status and need not apologize directly, they prefer to choose more casual words and use compensation strategies to explain their faults, so the degree of damage to face is relatively small. If the offender's status is low, he must humbly make a formal apology, assume corresponding responsibilities, and even accept punishment.

In Anglo-American culture, the value orientation of individualism is highly respected, while the factors of age and identity are in the second place. Old people and young people are equal. Whether the offender is the elder, the younger generation, or the superiors and subordinates, they must apologize. Apologies tend to be formal and sincere. According to the view of power gap, China belongs to the big power gap, while Britain and the United States are the opposite. Under the characteristics of big power gap, the hierarchy of superiors and subordinates is strict. Countries with small power gaps, such as Britain and the United States, have a more moderate hierarchical structure.In China, we basically follow the principle of "power is greater than right" and pursue the principle of power supremacy. So the privileges of those who have power are also reflected in apologies. Generally speaking, people with high social status need not apologize. If they apologize, they will break the established rules and disorder the order. Britain and the United States are countries with small rights gaps. They strongly advocate human rights, which are enjoyed equally by every citizen. Therefore, their interpersonal relationship tends to be parallel.

\section{Conclusion}

Apology is the basic manifestation of moral cultivation and an important part of civilized etiquette, which is common in both eastern and Western cultures. Once they have unintentionally offended others, they should apologize in time to make up for the infringement and respect the rights and interests of others. After careful identification of apologies in English and Chinese, we find the differences between cultural values. Culture and language are integrated. Culture derives language and language inherits culture. They are inseparable. In today's era of economic globalization, whether the world is interoperable or not has become a closely linked global village. When we conduct cross-cultural communication, we must recognize the huge cultural background behind language in order to ensure smooth language communication. Grasp apology terms in different language situations, clarify cultural differences, so as to promote close communication between different regional cultures.

\section{References}

[1] Ja Auxin. Intercultural Communication [M]. Shanghai: Shanghai Foreign Language Education Press, 1997

[2] Fao Lie. An Analysis of the Sentence Level Performance of Differences in Thinking between English and Chinese

[J]. Journal of Shanghai Radio and Television University, 2007, (3)

[3] Chaos Angelia. An Analysis of Apology Behavior and Apology Strategies in English-Chinese Communication [J]. Journal of Changchun Financial College. 2009 (02)

[4] Li Hangzhou. Approaches to Linguistic Studies [J]. Journal of North China Electric Power University (Social Science Edition). 2009 (02)

[5] Dong Xiongnu. Cross-cultural Study of Apology [J]. Journal of Human Medical University (Social Science Edition). 2008 (02) 